Григорова Я.В. Искусство и «нематериальный труд» // Вестник ПНИПУ. Культура. История. Философия. Право. 2017. - № 4. - C. 69-73. DOI: 10.15593/perm.kipf/2017.4.08

Grigorova Ya.V. Art and "non-material labour». Bulletin of PNRPU. Culture. History. Philosophy. Law, 2017, no. 4, pp. 69-73. DOI: 10.15593/perm.kipf/2017.4.08

DOI 10.15593/perm.kipf/2017.4.08

УДК 141

\title{
Я.В. Григорова
}

\section{ИСКУССТВО И «НЕМАТЕРИАЛЬНЫЙ ТРУД»}

В статье раскрываются основные особенности трансформации труда в современном обществе. Во второй половине двадцатого века значительно изменилось понятие труда, что связано с тенденцией к дематериализации, проявившейся во всех странах мира. Эта тенденция была отмечена философией постопераизма. Философы стремились развить «классический» категориальный аппарат марксистской философии. М. Хардт и А. Негри считали, что теория К. Маркса о труде должна быть пересмотрена. Результатом такого пересмотра стала новая категория, описывающая новый тип работы - нематериальный труд. По мнению М Хардта и А. Негри, нематериальный труд - это символическая и эмоциональная работа. П. Вирно отметил, что особенностью нематериального труда является «виртуозность». Речь идет о том, что процесс нематериального труда совпадает с его результатом, а его продукты носят событийный, аффрективный, символический характер. Виртуозность нематериального труда проявляется в особом воздействии на эмоциональную сферу реципиента труда. Автор продемонстрировал, что в философии постопераизма категория труда была освобождена от материального измерения, но философы так и не ответили на вопрос о причинах социальных изменений. Между тем концепция нематериального труда позволяет увидеть специфику современного общественного производства при условии использования данного понятия в контексте марксистской теории, а не вопреки ей.

В статье выдвигается гипотеза, что распространение нематериального труда в общественном производстве произошло после принятия капиталистической системой основных требований художественной критики, направленных против «общества труда». Анализируя идеи М. Лаззарато о Марселе Дюшане, автор подчеркивает, что именно в среде современного искусства зародилась новая трудовая этика, присущая нематериальному труду. В так называемом постфордистском обществе сопоставление искусства и общественного труда позволяет найти причины прекаризации современных работников. Делается вывод, что такая интерпретация причин появления нематериального труда помогает увидеть тенденцию его развития.

Ключевые слова: постопераизм, нематериальный труд, художественная критика, искусство, процесс прекаризации, трудовая этика, культуриндустрия, манипуляция символами и афффектами, постфордизм.

\section{Ya.V. Grigorova}

\section{ART AND “NON-MATERIAL LABOUR»}

General characteristic features of labour transformation in the modern society have been discovered in the article. It has been shown that in the second half of the XXth century considerable transformation of labour connected with dematerialization developed in all countries of the world. This tendency has been marked by post-operaism philosophy. Philosophers tried to develop "classical" categorical apparatus of Marxists' philosophy. M. Hardt and A. Negri have shown that labour theory of K. Marx should be revised. As a result of such revision they proposed new category which describes new type of work - non-material labour. In their opinion non-material labour is a symbolic and emotional work. P. Virno has noted that peculiar feature of non-material labour is the absence of product and virtuosity. The matter is that the process of non-material labour coincides with its result while its products are of eventual, affective, symbolic character. Virtuosity of nonmaterial labour is visualized in special influence on emotional sphere of the labour's recipient. The author demonstrated that the category of labour was released from material measuring in philosophy of post-operaism. But philosophers have not answered the question about the reasons of social changes. Mean while the concept of non-material labour makes possible to see specific character of the modern social production provided the given notion is used in the context of Marxist theory and not contrary to it.

The author of the article puts forward the hypothesis that distribution of non-material labour in social production happened after the main demands of artistic criticism directed against "the society of labour" had been adopted by capitalist system. Analyzing the ideas of V. Lazzarato about Marcel Duchamp the author has underlined that just in the environment of modern art new labor ethics characteristic for non-material labour was originated. Formation of the so called post-Ford society revealed that comparison of art and social labour allows finding the reasons of precarization of the modern workers. It is concluded that such interpretation of reasons for non-material labour appearance helps to identify the tendency of its development.

Keywords: post-operaism, non-material labour, artistic criticism, art, process of precarization, labour ethics, culture indusry, manipulation of symbols and affects, post-fordism.

Почему нестабильная занятость стала основой современного типа труда? Как и почему возникла рабочая сила, принимающая такие условия за атрибут современного типа труда? Где и почему произошло формирование новой этики трудовых отношений? В этой статье мы

(C) Григорова Яна Викторовна - старший преподаватель кафедры философии и права, ФГБОУ ВО «Пермский национальный исследовательский политехнический университет», e-mail: janasweet@mail.ru. 
попытаемся показать, как на эти вопросы отвечает философия итальянского постопераизма и какую роль в этом процессе сыграло искусство.

Структурные изменения экономических систем проявляется в стремительном распространении культурных индустрий, которые перемещаются от периферийных позиций в центр экономики. Такая трансформация повлияла на возникновение различных социальных концепций, пытающихся осмыслить труд в «культурном» секторе экономики: средствах массовой информации, кинематографии и звукозаписи, издательском бизнесе, производстве программного обеспечения, видеоигр, исполнительских видах искусства и т.д. Американский социальный географ Р. Флорида на обширном эмпирическом материале показал, что современная экономика развивается в местах, где сложился определенный рынок труда для творческих работников [1].

Важно, что этот вопрос затрагивается различными концепциями, которые пытаются осмыслить изменения, происшедшие в обществе в конце XX века. Здесь можно выделить «технологический подход», в соответствии с которым дематериализация связана с развитием информационно-коммуникационных технологий. «Культурологический подход», который делает акцент на медианасыщенности, повышенной информативности и символичности современной среды. «Постиндустриальный подход», согласно которому в основе общественных изменений лежит возрастание значения информации и переориентация производства товаров на производство услуг. Общим местом этих подходов является все та же простая констатация факта, что нематериальная сфера производства выходит на первый план [2].

Синхронность изменения труда и распространения культурных индустрий привлекла к себе внимание теоретиков постопераизма. Отметим, что идеи постопераизма оказали огромное влияние не только на социальную философию современности, но и на искусство конца XX - начала XXI века. Менее чем за полувековую историю своего существования постопераизм прошел путь от маргинальной группы итальянских левых «Potere Operaio» («Рабочая власть») до одной из наиболее цитируемых социально-философских концепций как в академической среде, так и в каталогах биеннале современного искусства [3].

Концепция постопераизма разрабатывается А. Негри, П. Вирно, М. Лаззарато, Г. Раунингом, Ф. Берарди. Авторы творчески соединили марксистский подход с лингвистическим поворотом в философии, получив тем самым категориальный аппарат, который достаточно точно описывает ситуацию сближения новых форм труда и новых художественных практик.

Для обозначения современной стадии капитализма постопераизм пользуется концепцией постфордизма. Не отказываясь от метода марксовой теории, философы отмечают: «...коль скоро история движется вперед, а социальная реальность изменяется, то прежние теории уже непригодны. Для новой действительности требуются новые концепции» [4, с. 180]. В последние сорок лет XX века общественное производство существенно изменилось. Такие изменения, по мнению постопераистов, было невозможно предвидеть в 1857 году, когда К. Маркс написал «Критику политической экономии. Черновой набросок 1857-1858 гг.» [5]. Со времен К. Маркса капиталистическое производство прошло путь от классического капитализма к фордизму и постфордизму. Если фордистский этап был связан с появлением массового конвейерного производства, то постфордизм возник на основе дематериализации производства.

Согласно постопераистам, с середины XX века промышленный труд теряет свои ведущие позиции, отвоеванные в XIX веке у сельскохозяйственного труда. Новой ведущей формой труда становится труд, включающий в себя два важнейших аспекта: манипуляцию символами и манипуляцию аффектами [4, с. 139]. Философия постопераизма назвала такой труд нематериальным. Авторы отмечают, что нематериальный труд проникает во все сферы: экономические, политические, социальные, культурные. Дополняя определение нематериального 
труда, М. Хардт и А. Негри называют такой труд биополитическим. «Труд биополитический, то есть такой, в результате которого создаются не только материальные блага, но и взаимоотношения, и в конечном счете - сама общественная жизнь» [4, с. 140]. Иными словами, под нематериальным трудом постопераизм понимает интеллектуальный труд, направленный не на создание конечного продукта, а на производство самого человека.

Распространение культурных индустрий способствовало развитию нематериального труда. Заимствуя понятие культуриндустрии (Kulturindustrie) из работ немецких философов Т. Адорно и М. Хоркхаймера [6], Вирно показывает, что центральным элементом культурной индустрии является «виртуозность» [7, с. 160]. Для прояснения этого феномена П. Вирно берет примеры из мира искусства: искусный музыкант, танцор, актер театра. Все те, чья деятельность перестает существовать после акта исполнения, деятельность которых совпадает с процессом производства. Ее продукты носят событийный, аффективный, символический характер, не фиксируемый в овеществленных результатах. Как считает П. Вирно, виртуозная деятельность становится «королевой производительных сил».

Итак, теоретические усилия постопераизма направлены на выработку новых категорий, способных схватить и объяснить происшедшие перемены и обозначить тенденции развития труда. Введенные ими понятия «нематериального труда», «виртуозности» тем не менее не до конца решают указанную задачу. Без ответа остался важный вопрос: что повлияло на тенденцию к дематериализации общественного производства?

Чтобы ответить на вопрос о причинах дематериализации труда, необходимо знать, как на эту ситуацию повлияло искусство. Распространение постфордистской экономики и ведущей роли нематериального труда совпало с так называемой «дематериализацией» произведения искусства в концептуализме и постконцептуализме. Знаковой фигурой в этом процессе считается М. Дюшан. Дематериализация произведения искусства выразилась в технике редимейда, когда художник перестает сам творить предмет, вкладывая в него только определенную идею, которая не существует без публики. «Реди-мейд - не объект, не картина, ибо его нужно рассматривать, «отворачивая голову». С этой точки зрения мы можем определить его как технику разума, одновременно и десубъективирующую, и производящую новую субъективность $[8,49]$. Как считает М. Лаццарато, М. Дюшан своим искусством совершил нападение на труд, как на одну из важнейших основ капиталистического общества. «Дюшан упорно отказывается работать - идет ли речь о наемном труде или о труде творческом. Он отказывается подчиняться обязанностям, ролям и нормам капиталистического общества» [8, с. 15].

Мир искусства в 60-70-х годах XX века обрушился с художественной критикой на индустриальное общество. Эта критика была направлена, как отмечают Л. Болтански и И. Кьяпелло, на два источника возмущения: с одной стороны, разочарование и ощущение неподлинности, с другой - угнетение. Художники акцентировали внимание на утрате смысла прекрасного. Упор делался на то, что капитализм все превращает в товар, подчиняет людей механизированным трудом, лишает свободы и творчества [9, с. 698].

Дематериализация в искусстве также проявилась в практиках кураторства. В те же годы, как отмечает В. Мизиано, совокупность художественных событий привела к появлению фигуры куратора, который и стал олицетворением нематериального труда в сфере искусства. «Кураторская практика представляется адекватной определению нематериального производства почти в буквальном смысле этого слова» $[10,20]$. Куратор вкладывает в выставку свои идеи, социальные связи, интеллектуальный багаж, способности к коммуникации. В целом искусство стало тяготеть к нематериальности. 
Каким же образом удалось инкорпорировать художественные ценности в мир капиталистического накопления? Социальная мысль обратила внимание на то, что именно в искусстве зародилась трудовая этика, присущая новой рабочей силе. «Эта рабочая сила возникла в результате “тихой революции”, разворачивающейся внутри антропологических реальностей работы, внутри реконфигурации ее смыслов» [11], - отмечает Лаццарато. Важно отметить, что исторически статус художественного труда долгое время ставился под сомнение. Деятельность художника, если она не была связана с физическим трудом, считалась божьим даром, следовательно, не требовала денежного вознаграждения. Даже в 30-х годах XX века считалось, что человек искусства не может являться наемным работником, то есть получать заработную плату [12]. Однако капиталистическое общество не обошло своим вниманием мир искусства. «Качества, которые особенно ценятся в постиндустриальной экономике, - коммуникативность, красноречие, креативность и оригинальность, способность мыслить в границах отдельного проекта на условиях временного контракта или вовсе без такового, готовность к гибкому рабочему графику, физическая и интеллектуальная мобильность, - до того приобрели определяющую роль (чтобы сохранить ее и поныне) в области искусства» [13, с. 9].

Как убедительно показал Э. Росс, полное вовлечение художника в наемный труд произошло в 90-е годы XX века. В книге «Без воротничка» Э. Росс описал, как художественная жизнь была приспособлена к новому типу бизнеса [14]. Д. Брукс отмечает, «представители новой элиты информационного века - это богемные буржуа (bourgeois bohemians)» [15, c. 3]. Таким образом, субъект нематериального труда возник как гибрид между неустойчивой, нестабильной жизнью художника или интеллектуала и стремлением к ценностям капиталистического общества.

Искусство стало «лабораторией» нематериального труда, который распространился на все общество. Дело в том, что большинство требований художественной критики 60-80 годов $\mathrm{XX}$ века были приняты капиталистическим производством. Работник получил большую свободу деятельности, творчество, мобильность, возможность проявлять свою индивидуальность. Важную роль в этом процессе сыграла художественная критика труда.

Суммируя все сказанное, отметим, что субъект нематериального труда сформировался под воздействием искусства. Однако, впитав в себя ценности творческого образа жизни, новая рабочая сила оказалась в ловушке нестабильной занятости, прекарности. Важной особенностью нового труда является увлеченность и даже жертвенность работника. Неограниченный круг обязанностей, невозможность отделить работу от досуга, так как «тебе интересно, ты увлечен, вовлечен, и это сильно сплетается с твоей жизнью» [16]. Ожидаемое вознаграждение в таком труде характеризуется высокой степенью неуверенности. Большинство работников не имеют никакой гарантии непрерывной занятости, работают по временным и краткосрочным контрактам, без социальных гарантий.

Художественная критика общества труда была обусловлена кризисом фордизма. Искусство повлияло на формирование нестабильного, прекарного, но все же творческого труда. Теперь остается надеяться, что искусство сформирует активного социального субъекта способного разрешить проблемы постфордистского общества.

\section{Список литературы}

1. Флорида Р. Креативный класс: люди, которые меняют будущее. - М.: Классика-ХХІ, 2005. $-422 \mathrm{c}$.

2. Уэбстер Ф. Теории информационного общества. - М.: Аспект Пресс, 2004. - 400 с.

3. Pasquinelli Matteo The so-called Italian Theory and the revolt of living knowledge [Электронный ресурc]. - URL: http://www.uninomade.org/italian-theory-en/ (accessed at 28 September 2017). 
4. Хардт М., Негри А. Множество: война и демократия в эпоху империи. - М.: Культурная революция, 2006. -559 с.

5. Маркс К. Экономические рукописи 1857 - 1859 гг. // Маркс К., Энгельс Ф. Соч. 2-е изд. - Т. 46. - Ч. 2.

6. Хоркхаймер М., Адорно Т. Диалектика просвещения. - СПб.: Медиум: Ювента, 1997. $310 \mathrm{c}$.

7. Вирно П. Грамматика множества: к анализу форм современной жизни. - М.: Ад Маргинем, 2013. - $170 \mathrm{c}$.

8. Лаццарато М. Марсель Дюшан и отказ трудиться. - М.: Grundrisse, 2017. - 96 с.

9. Болтански Л., Кьяпелло Э. Новый дух капитализма. - М.: НЛО, 2011. - 976 с.

10. Мизиано В. Пять лекций о кураторстве. - М.: Ад Маргинем, 2015. - 232 с.

11. Лаззарато М. Нематериальный труд [Электронный ресурс] // Худож. журн. - 2008. № 69. - URL: http://moscowartmagazine.com/issue/23/article/369 (дата обращения: 28.09.2017).

12. Кастель Р. Метаморфозы социального вопроса. Хроника наемного труда. - СПб.: Алетейя, 2011. - 574 с.

13. Гилен П. Бормотание художественного множества. Глобальное искусство, политика и постфордизм. - М.: Ад Маргинем, 2016. - 287 с.

14. Andrew Ross No-collar: The Humane Workplace its Hidden Costs. - Philadelphia: Temple University Press, 2004. - P. 123-160.

15. Брукс Д. Бобо в раю: откуда берется новая элита. - М.: Ад Маргинем, 2013. - 296 с.

16. Абрамова Е. «Менеджер» vs «девочка» [Электронный ресурс]. - URL: http://archives.colta.ru/docs/21801 (дата обращения: 09.09.2017).

\section{References}

1. Florida R. Kreativnyi klass: liudi, kotorye meniaiut budushchee [Creative class: people who change the future]. Moscow, Klassika-XXI, 2005, $422 \mathrm{p}$.

2. Webster F. Teorii informatsionnogo obshchestva [Theories of the information society]. Moscow, Aspekt Press, $2004,400 \mathrm{p}$.

3. Pasquinelli M. The so-called Italian Theory and the revolt of living knowledge, available at: http://www.uninomade.org/italiantheory-en/ (accessed 28 October 2017).

4. Hardt M., Negri A. Mnozhestvo: voina i demokratiia v epokhu imperii [War and democracy in the age of the empire]. Moscow, Kul'turnaia revoliutsiia, 2006, $559 \mathrm{p}$.

5. Marx K. Ekonomicheskie rukopisi 1857-1859 godov [Economic manuscripts of 1857 - 1859 years]. Sochineniia. 2nd ed., vol. 46, part 2, $239 \mathrm{p}$.

6. Horkheimer M., Adorno T. Dialektika prosveshcheniia [Dialectics of Enlightenment]. Saint Petersburg, Medium, luventa, $1997,310 \mathrm{p}$.

7. Virno P. Grammatika mnozhestva: $k$ analizu form sovremennoi zhizni [Grammar of the set: to the analysis of the forms of modern life]. Moscow, Ad Marginem, 2013, $170 \mathrm{p}$.

8. Lazzarato M. Marsel' Diushan i otkaz trudit'sia [Marcel Duchamp and refusal to work]. Moscow, Griundesse, 2017, 96 p.

9. Boltanski L., Kyapello E. Novyi dukh kapitalizma [The new spirit of capitalism]. Moscow, Novoe Literaturnoe Obozrenie, 2011, 976 p.

10. Misiano V. Piat' lektsii o kuratorstve [Five lectures on supervision]. Moscow, Ad Marginem, 2015, $232 \mathrm{p}$.

11. Lazzarato M. Nematerial'nyi trud [Intangible labor], available at: http://eipcp.net/transversal/1106/lazzarato/ru (accessed 28 September 2017).

12. Castel R. Metamorfozy sotsial'nogo voprosa. Khronika naemnogo truda [Metamorphoses of the social question. Chronicle of wage labor]. Saint Petersburg, Aleteiia, 2011, 574 p.

13. Gielen P. Bormotanie khudozhestvennogo mnozhestva. Global'noe iskusstvo, politika i postfordizm [Mutter of the artistic set. Global art, politics and post-fordism]. Moscow, Ad Marginem, 2016, $287 \mathrm{p}$.

14. Ross A. No-collar: The Humane Workplace its Hidden Costs. Philadelphia: Temple University Press, 2004, pp. 123-160.

15. Bruks D. Bobo $v$ raiu: otkuda beretsia novaia elita [Bobo in paradise: where does the new elite come from]. Moscow, Ad Marginem, 2013, 296 p.

16. Abramova E. «Menedzher» vs «devochka» ["Manager" vs "girl"], available at: http://archives.colta.ru/docs/21801 (accessed 9 September 2017).

Получено: 10.10.2017

Принято к печати: 30.10.2017 